\title{
Influence of Sodium and Maturity Stage on the Antioxidant Properties of Cauliflower and Broccoli Sprouts
}

\author{
Antoanela PATRAS ${ }^{1 *}$, Vasile STOLERU ${ }^{1}$, Razvan Vasile FILIMON ${ }^{1,2}$, Silvica \\ PADUREANU ${ }^{3}$, Elena Liliana CHELARIU ${ }^{1}$, Costas G. BILIADERIS ${ }^{4}$
}

\author{
${ }^{1}$ University of Agricultural Sciences and Veterinary Medicine of Iasi, Faculty of Horticulture, 3 Mihail Sadoveanu Alley, 700490 Iaşi, \\ Romania; apatras@uaiasi.ro (*correspondingauthor);vstoleru@uaiasi.ro; razvan_f80@yahoo.com; julia@uaiasi.ro \\ ${ }^{2}$ Research Development Station for Viticulture and Winemaking, 48 M. Sadoveanu Alley, 700489 Iaşi, Romania \\ ${ }^{3}$ University of Agricultural Sciences and Veterinary Medicine of Iasi, Faculty of Agriculture, \\ 3 Mihail Sadoveanu Alley, Iaşi, Romania; silvyp27@yahoo.com \\ ${ }^{4}$ Aristotle University of Thessaloniki, Faculty of Agriculture, University Campus, 54124 Thessaloniki, Greece; biliader@agro.auth.gr
}

\begin{abstract}
Sprouts are very rich in antioxidants (e.g. phenolic compounds) and their consumption is beneficial for humans' health. The sprouts' antioxidant properties are correlated to conditions of growth and maturity stage. The present study reveals the influence of maturity stage (5-, 7- and 9-day-old) and two sodium salts, $\mathrm{NaCl}$ and $\mathrm{Na}_{2} \mathrm{SO}_{4}(10 \mathrm{mM}$ and $100 \mathrm{mM}$ ) on the antioxidant capacity and total phenolic content of cauliflower and broccoli sprouts. The analysed sprouts' extracts were obtained in two phases, using ethanol $70 \%$ with $0.01 \%$ hydrochloric acid. In the case of cauliflower, the 7 days germination leads to the highest total phenolic content and radical scavenging capacity. Broccoli sprouts revealed the most enhanced DPPH radical scavenging capacity and total phenolic content at 5-day-old. The two sodium salts, generally, had positive effects on global antioxidant status. It is highlighted both for broccoli and cauliflower, the stimulating effect of $100 \mathrm{mM} \mathrm{Na}_{2} \mathrm{SO}_{4}$ on the total phenolic content and soluble dry weight, but the DPPH radical scavenging activity was more important in the case of $\mathrm{NaCl}$, than $\mathrm{Na}_{2} \mathrm{SO}_{4}$ treatments, except for cauliflower sprouts treated with $100 \mathrm{mM} \mathrm{Na}_{2} \mathrm{SO}_{4}$. In conclusion, germination under adequate salt stress is a protocol to be considered in order to improve antioxidant properties of broccoli and cauliflower sprouts, despite the non-convenient effects on the germination and sprouts growth. Further researches are needed to optimize the level and time periods of such treatments.
\end{abstract}

Keywords: "biofactories" of health-promoting compounds, Brassica oleracea, hydroethanolic extract, polyphenolic content, salt stress, sodium chloride, sodium sulphate

Abbreviations: AC, anthocyanin content; DPPH, 2,2-diphenyl-1-picrylhydrazyl; FW, fresh weight; GAE, gallic acid equivalents; RSC, radical scavenging capacity; TPC, total phenolic content; TPC-D280, total phenolic content determined by absorbance at $280 \mathrm{~nm}$; TPC-FC, total phenolic content determined by Folin-Ciocâlteu method; SDM, soluble dry matter

\section{Introduction}

At present time, the interest for healthy nutrition and functional foods is continuously expanding. Among functional products, an important position is held by sprouts, which are very rich, not only in nutritive, but also in bioactive compounds (especially antioxidants) having various beneficial properties for health: e.g. cardio-vascular protection, anticarcinogenity, prevention of age- and stressrelated diseases. Some health-protecting phytochemicals can be found in sprouts in much higher concentration than in mature plants or seeds (Sousa et al., 2009; Cevallos-Casals and Cisneros-Zevallos, 2010). Sprouts are easy to cultivate both at industrial and home level and bring not only health, but also economic advantages, as their production is simple and inexpensive comparing to their market price.

Germination can be used as a method to increase nutritive and functional characteristics and to reduce the potential anti-nutrients existing in seeds and mature plants (Gulewicz et al., 2014). Germination mobilizes reserve nutrients required for plant growth, by hydrolysing proteins and storage carbohydrates, in order to obtain the required substrates for the seedling development. At same time, the contents of minerals and vitamins, such as the B-group 
vitamins and ascorbic acid, as well as simple sugars, are increased. Moreover, germination increases the content in antioxidant compounds (like polyphenols, vitamins) and thereby the antioxidant potential of the plant material (Frias et al., 2005).

Phenolic compounds are produced in plants through the phenylpropanoid pathway and contribute substantially to the antioxidant capacity of Brassica oleracea varieties, as they are known to be their major antioxidants (Podsedek, 2007; Soengas et al., 2012; Kaulmann et al., 2014). LópezAmorós et al. (2006) found that germination modifies quantitatively and qualitatively the phenolic composition of peas, lentils and beans, and the changes depend on the type of plant and germination conditions. Among these, the duration of germination is one of the most important factors, as there are significant differences between the compositions of sprouts at different developmental stages. Previous studies also proved that the germination technique (e.g. type and duration of illumination, temperature, humidity) and different environmental stresses and elicitors (e.g. salts, radiations) can increase the content of bioactives, the antioxidant potential and the anticarcinogenic properties of some sprouts (Dkhil and Denden, 2010; Baenas et al., 2014). Moreira-Rodríguez et al. (2017) studied recently the possibilities to use UVA and UVB light to increase polyphenolic and glucosinolate content in 7-dayold broccoli sprouts.

Yuan et al. (2010) studied the influence of different concentrations of $\mathrm{NaCl}(10,50$ and $100 \mathrm{mM})$ on phenolic content and antioxidant activity in radish sprouts. Their conclusion was that salt stress provoked with $100 \mathrm{mM}$ $\mathrm{NaCl}$ could substantially improve them (Yuan et al., 2010). Patras et al. (2013) found that $\mathrm{NaCl}$ in very small concentration $(0.2 \mathrm{mM})$ is stimulating the white cabbage germination and the biosynthesis of chlorophyll $a$ and $b$. Wang et al. (2009) stated that salt and drought stresses during the germination of alfalfa tolerant cultivar are associated with enhanced activity of antioxidant enzymes.

It is noticeable the modern tendency of scientists to use abiotic stresses in order to transform plants in "biofactories" of health - promoting phytochemicals, which produce and accumulate high levels of secondary metabolites (especially antioxidants) with many potential applications in food, pharmaceutical and cosmetic industries (Jacobo-Velázquez and Cisneros-Zevallos, 2012). Sprouts cultivated under certain conditions may become the most suitable "biofactories" for polyphenols, as they proved to have all the prerequisites.

Based on global trends in nutrition and on the groundwork of actual knowledge in matter of sprout's growth, our present interest focuses on improving the health - promoting potential of two varieties of Brassica oleracea sprouts, by using non-conventional conditions for germination, in order to stimulate the biosynthesis of polyphenolics (the main antioxidants in Brassicaceae). This present study explores the effects of germination duration (5, 7 and 9 days) and two sodium salts $-\mathrm{NaCl}$ and $\mathrm{Na}_{2} \mathrm{SO}_{4}$ administrated in two concentrations, on the total phenolic content and antioxidant properties, reflected by radical scavenging capacity, of broccoli and cauliflower sprouts.

\section{Materials and Methods}

\section{Plantmaterial}

The seeds were purchased from the market: 'Premium' broccoli (Brassica oleracea L., convar. botrytis subvar. cymosa Lam.) seeds especially designated for sprouting and 'Gigante di Napoli' cauliflower (Brassica oleracea L., convar. botrytis subvar. cauliflora Alef.) seeds.

\section{Sprouting conditions}

Firstly, the seeds were sterilised with $0.07 \% \mathrm{NaOCl}$, rinsed and soaked in distilled water for $10 \mathrm{~h}$. The peat-based germination substrate (DSM 2w, from Kekkilä Garden Professional Substrate) was also sterilized at $90-95^{\circ} \mathrm{C}$ for 1 h. The imbibed seeds were then spread in trays containing the substrate (Vale et al., 2015). Sprouting was performed 5, 7 and 9 days in a plant growth chamber MLR - 351 (Sanyo), for the first $60 \mathrm{~h}$ at $24^{\circ} \mathrm{C}$, relative humidity $80 \%$, lighting with $2 \times 40 \mathrm{~W}$ fluorescent lamps, and for the rest of time ( $60 \mathrm{~h}, 108 \mathrm{~h}$ and $156 \mathrm{~h}$, respectively) at $22^{\circ} \mathrm{C}$, relative humidity $80 \%$ and lighting with $9 \times 40 \mathrm{~W}$ fluorescent lamps. Four parallel treatments (salt concentration and type) were applied to the substrate containing the seeds: 10 $\mathrm{mM} \mathrm{NaCl}, 100 \mathrm{mM} \mathrm{NaCl}, 10 \mathrm{mM} \mathrm{Na}_{2} \mathrm{SO}_{4}$ and $100 \mathrm{mM}$ $\mathrm{Na}_{2} \mathrm{SO}_{4}$. The control was watered normally, with distilled water, while in case of treated variants, the sodium salts solutions replaced the water during 9 days. In order to study the effects of maturity stage, untreated sprouts were harvested at the age of 5-, 7- and 9-day-old and for the research of the two sodium salts influences, sprouts were harvested only at 9-day-old, because 5-and 7-day-old treated sprouts were very small and undeveloped and therefore improper to be used as food ingredient.

\section{Soluble dry matter}

The soluble dry matter (SDM) was determined from whole sprouts, at $20^{\circ} \mathrm{C}$, using the digital DR301-95 Krüss refractometer. Results were expressed as ${ }^{\circ} \mathrm{Bx}$.

\section{Extraction}

Each experimental variant of sprouts was extracted in triplicate, following a two-steps procedure, using as solvent $70 \%$ ethanol acidified with $0.01 \%$ hydrochloric acid:

1. A portion of exactly weighed sprouts $3.27 \pm$ $0.02 \mathrm{~g}$ were ground in the presence of $1.5 \mathrm{~g}$ quartz sand for $1 \mathrm{~min}$ and $40 \mathrm{~s} \pm 10 \mathrm{~s}$ and mixed with $15 \mathrm{~mL}$ solvent. The extraction was conducted for $30 \mathrm{~min}$ on a water-bath at $38 \pm 1{ }^{\circ} \mathrm{C}$ under continuously shaking, followed by centrifugation at $7000 \mathrm{rpm}, 15$ min. The supernatant was then transferred in a brown bottle.

2. The residue remaining from the previous extraction step was taken up with $10 \mathrm{~mL}$ solvent and re-extracted for another $15 \mathrm{~min}$ on the water-bath at $38 \pm 1{ }^{\circ} \mathrm{C}$, under shaking, followed by centrifugation at $7000 \mathrm{rpm}, 15$ min. The resulted supernatant was mixt with the first extracted fraction and stored at $4{ }^{\circ} \mathrm{C}$. 
460

\section{Total phenolic content}

The content of total polyphenols (TPC) was determined using two methods:

1. Folin-Ciocâlteu method (TPC-FC), which measures all phenolic compounds with reducing properties (Ribéreau-Gayon et al., 2006). It is also known as an indicator for total reducing capacity (Ragusa et al., 2016). Briefly, $0.1 \mathrm{~mL}$ sample, 7.4 $\mathrm{mL}$ distilled water, $0.5 \mathrm{~mL}$ Folin-Ciocâlteu reagent and $2 \mathrm{~mL}$ of $20 \% \mathrm{Na}_{2} \mathrm{CO}_{3}$ were vortexed and the mixture was kept in the dark for $30 \mathrm{~min}$. The blank preparation followed the same procedure, replacing the sample with $0.1 \mathrm{~mL}$ distilled water. The absorbance was read at $750 \mathrm{~nm}$. Results were calculated from a calibration curve with gallic acid (0-300 mg gallic acid/L, $\left.\mathrm{R}^{2}=0.9913\right)$ and expressed as gallic acid equivalents on a fresh weight basis (mg GAE/100 g FW).

2. Direct reading of sample absorbance at $280 \mathrm{~nm}$ (TPC-D280), which presents advantages as speed and reproducibility and is based on the light absorbance of the aromatic rings. The method is described by Ribéreau-Gayon et al. (2006). The samples were previously appropriate diluted. The results were expressed as gallic acid equivalents per fresh weight (mg GAE/100 g FW) using a calibration curve $\left(0-50 \mathrm{mg}\right.$ gallic acid $/ \mathrm{L}, \mathrm{R}^{2}=$ 0.9958).

\section{Anthocyanin content}

The total content of monomeric anthocyanins (AC) was determined by the $\mathrm{pH}$ differential method (RibéreauGayon $e t$ al., 2006). Two mixtures were prepared by adding $10 \mathrm{~mL}$ of $\mathrm{pH} 0.6$ solution and, respectively, $\mathrm{pH} 3.5$ buffer, to a mixture of $1 \mathrm{~mL}$ sample and $1 \mathrm{~mL}$ of $96 \%$ ethanol containing $0.1 \% \mathrm{HCl}$. Absorbances of both mixtures were read at $520 \mathrm{~nm}$ against a blank with distilled water. The results were calculated with the formula: Absorbance $=$ $\mathrm{Abs}_{520 \mathrm{pH}} 0.6-\mathrm{Abs}_{520 \mathrm{pH} 3.5}$ (where $\mathrm{Abs}_{520} \mathrm{pH} 0.6=$ absorbance of the $\mathrm{pH} 0.6$ mixture, at $520 \mathrm{~nm}$ and $\mathrm{Abs}_{520} \mathrm{pH} 3.5=$ absorbance of the $\mathrm{pH} 3.5$ mixture, at $520 \mathrm{~nm}$ ) and expressed from a calibration curve with cyanidin-3glucoside, and reported as $\mathrm{mg} / 100 \mathrm{~g} \mathrm{FW}$.

\section{Radical scavenging capacity}

The ability of sprouts extracts to scavenge free radicals was determined using the $\mathrm{DPPH}^{\circ}$ radical scavenging method (Brand-Williams et al., 1995, with modifications). The absorbance of $\mathrm{DPPH}^{*}$ stable radical at $515 \mathrm{~nm}$ is decreasing in presence of antioxidants as a consequence of $\mathrm{DPPH}^{\bullet}$ reduction. A methanolic $\mathrm{DPPH}^{\bullet}$ stock solution of $0.6 \mathrm{mM}$ was prepared and diluted 5 times with methanol to obtain the working solution $(0.12 \mathrm{mM})$. In order to estimate the radical scavenging capacity (RSC) of extracts, $1.3 \mathrm{~mL}$ extract was added to $2.6 \mathrm{~mL} \mathrm{DPPH}^{\circ}$ working solution (the ratio extract:DPPH ${ }^{*}=1: 2$, according to Kevers et al., 2007), and after 5 min of incubation in the dark, the absorbance at $515 \mathrm{~nm}$ was read against methanol $\left(\mathrm{A}_{(5)}\right)$. The absorbance of a control containing $2.6 \mathrm{~mL}$ $\mathrm{DPPH}^{\circ}$ and $1.3 \mathrm{~mL}$ of extraction solvent $(70 \%$ ethanol acidified with $0.01 \% \mathrm{HCl}$ ) was measured $\left(\mathrm{Ac}_{(\circ)}\right)$ and the obtained value range between $0.65-0.75$. The $\mathrm{DPPH}^{*}$ radical scavenging capacity of the extracts or the percentage of $\mathrm{DPPH}^{*}$ inhibition was calculated with the formula:

$\mathrm{DPPH}^{*}$ radical scavenging capacity $(\%)=\left[\left(\mathrm{Ac}_{(0)}-\right.\right.$ $\left.\left.\mathrm{A}_{(5)}\right) / \mathrm{Ac}_{(0)}\right] \times 100$,

where $\mathrm{Ac}_{(\mathrm{o})}$ is the control absorbance at the initial moment $(\mathrm{t}=0 \mathrm{~min})$ and

$\mathrm{A}_{(5)}$ is the absorbance of $\mathrm{DPPH}^{\cdot}$ in the presence of extract at $t=5 \mathrm{~min}$.

The $\mathrm{DPPH}^{\bullet}$ radical scavenging capacity can be reported relative to a standard antioxidant, as ascorbic acid. Our results were expressed as 'equivalent' mg of ascorbic acid per $100 \mathrm{~g}$ of fresh weight (mg ascorbic acid/100 $\mathrm{g} \mathrm{FW}$ ), from a calibration curve $\left(R^{2}=0.9964\right)$.

\section{Statistical analysis}

All analyses were performed in triplicate. Reported numeric values are means \pm standard deviations $(\mathrm{SD})$. Oneway analysis of variance (ANOVA), and post-hoc Tukey Honestly Significant Difference (HSD) for multiple comparison test were performed using IBM SPSS Statistics 21 software, in order to analyse the data. Differences at $\mathrm{p}<$ 0.05 were treated as significant. Correlation analyses were performed using Microsoft Excel 2010.

\section{Results and Discussion}

\section{Soluble dry matter}

The most important content in soluble dry matter of untreated sprouts was registered at 9-day cauliflower and broccoli sprouts, whereas differences between developmental stages were not statistically significant (Table 1). Treatments with $10 \mathrm{mM} \mathrm{NaCl}$ and $10 \mathrm{mM} \mathrm{Na}_{2} \mathrm{SO}_{4}$ slightly decreased SDM content in both Brassica sprouts, and 100 $\mathrm{mM} \mathrm{NaCl}$ slightly increased it only in cauliflower (in broccoli was obtained same value), but all these variations were not significant statistically. The only important modifications noted were the significant increases of SDM contents in the presence of $100 \mathrm{mM} \mathrm{Na}_{2} \mathrm{SO}_{4}$, for broccoli sprouts from $3.38 \pm 0.46$ to $5.08 \pm 0.18^{\circ} \mathrm{Bx}$, and more than that, for cauliflower sprouts from $3.35 \pm 0.49$ to $5.95 \pm 0.21$ ${ }^{\circ} \mathrm{Bx}$. Other authors affirmed that the conditions of germination cause changes in sugars, starch as well as enzymes involved in carbohydrate metabolism in sprouts (Dkhil and Denden, 2010; Baenas et al., 2014), which can be reflected in SDM content. It was expected that an aggressive salt stress, as it is $100 \mathrm{mM} \mathrm{Na} 2 \mathrm{SO}_{4}$, to determine increase in soluble dry matter content, also, as a consequence of plant dehydration that was visually observed only in case of this treatment.

\section{Total phenolic content}

Both methods showed, in general, similar evolution of total phenolic content over time and under each specific treatment (Fig. $1 \mathrm{~A}, \mathrm{~B}$ ), but values obtained using D280 were largely increased, presumably due to the presence of other aromatic compounds (e.g. vitamin $\mathrm{B}_{2}$, amino acids, peptides and proteins containing aromatic amino acids, aromatic glucosinolates and isothiocyanates) which absorb light at $280 \mathrm{~nm}$, besides the reducing phenols. Without exception, 'Gigante di Napoli' cauliflower sprouts were 
Table 1. Soluble dry matter $\left({ }^{\circ} \mathrm{Bx}\right)$ of untreated (5-, 7- and 9-day-old) and 9-day-old treated (with $\mathrm{NaCl}_{\text {or }} \mathrm{Na}_{2} \mathrm{SO}_{4}$ ) cauliflower and broccoli sprouts

\begin{tabular}{|c|c|c|c|}
\hline \multicolumn{2}{|c|}{ Variant of sprouts/treatment } & Cauliflower & Broccoli \\
\hline \multirow{3}{*}{ Untreated } & 5-day-old & $2.80 \pm 0.14 \mathrm{ab}$ & $3.33 \pm 0.53 \mathrm{a}$ \\
\hline & 7-day-old & $2.40 \pm 0.14 \mathrm{a}$ & $2.98 \pm 0.11 \mathrm{a}$ \\
\hline & 9-day-old & $3.35 \pm 0.49 \mathrm{ab}$ & $3.38 \pm 0.46 \mathrm{a}$ \\
\hline \multirow{4}{*}{ 9-day-old treated } & $\mathrm{NaCl}, 10 \mathrm{mM}$ & $2.60 \pm 0.14 \mathrm{ab}$ & $2.90 \pm 0.14 \mathrm{a}$ \\
\hline & $\mathrm{NaCl}, 100 \mathrm{mM}$ & $3.60 \pm 0.14 b$ & $3.38 \pm 0.11 \mathrm{a}$ \\
\hline & $\mathrm{Na}_{2} \mathrm{SO}_{4}, 10 \mathrm{mM}$ & $2.60 \pm 0.28 \mathrm{ab}$ & $3.20 \pm 0.71 \mathrm{a}$ \\
\hline & $\mathrm{Na}_{2} \mathrm{SO}_{4}, 100 \mathrm{mM}$ & $5.95 \pm 0.21 \mathrm{c}$ & $5.08 \pm 0.18 b$ \\
\hline
\end{tabular}

Note: Data represent mean value of soluble dry matter \pm standard deviation expressed in ${ }^{\circ} \mathrm{Bx}$. Different letters denote significant differences between variants of same variety (Tukey HSD test, $\mathrm{p}<0.05$ )

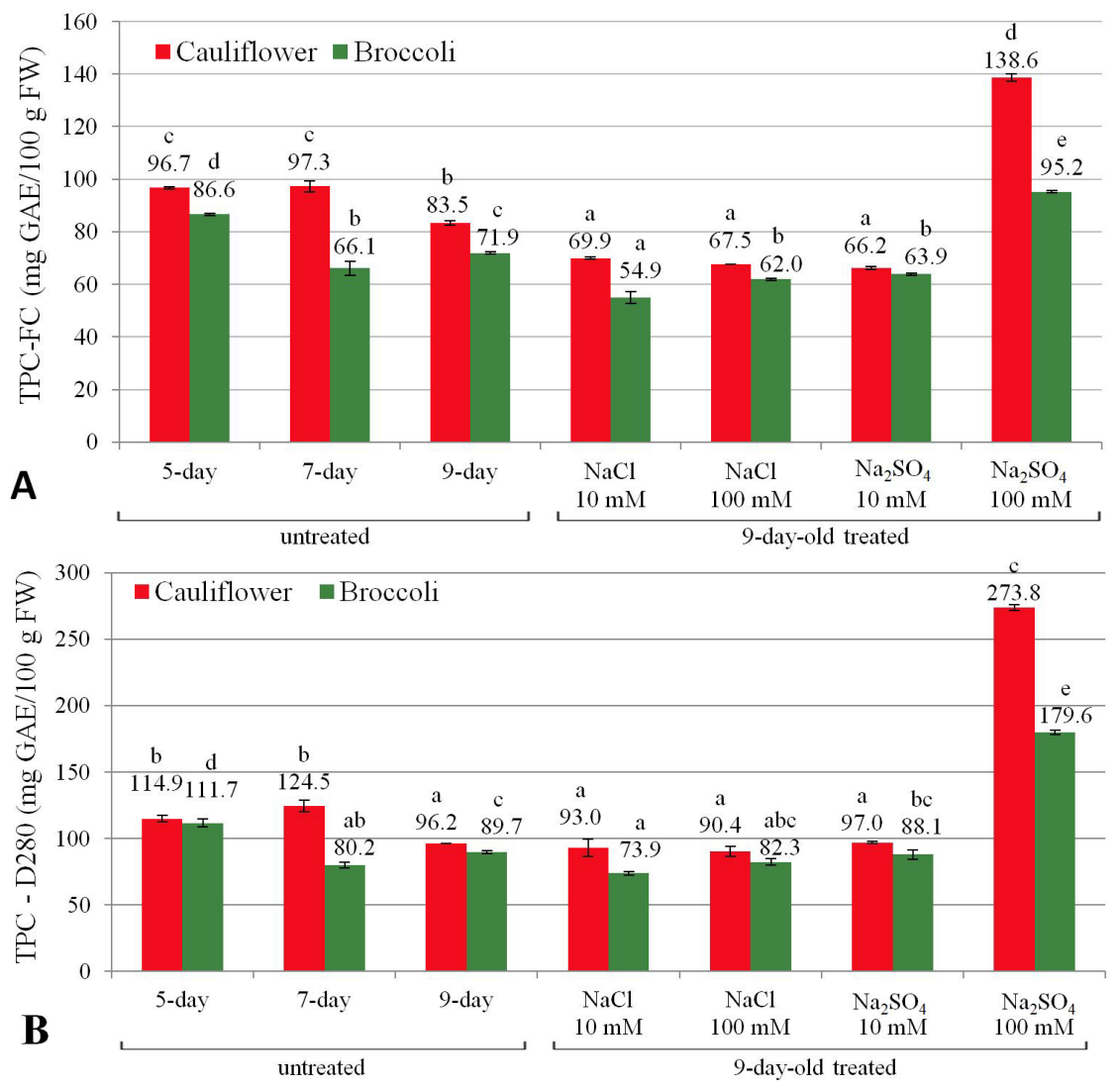

Fig. 1. Total phenolic content (TPC) of untreated (5-, 7- and 9-day-old) and 9-day-old treated (with $\mathrm{NaCl}$ or $\mathrm{Na}_{2} \mathrm{SO}_{4}$ ) cauliflower and broccoli sprouts. A - Folin-Ciocalteu method (TPC-FC) and B - D280 method (TPC-D280). Different letters denote significant differences between variants of same variety (Tukey HSD test, $\mathrm{p}<0.05$ )

richer in phenolic compounds than 'Premium' broccoli sprouts. Similar results were obtained by other authors, who found in broccoli sprouts the lower amount of total phenolics, from a series of edible sprouts, after kohlrabi, cabbage, and other Brassicaceae (Lim et al., 2013).

In cauliflower, both methods proved that the TPC slightly increases from 5- to 7-day-old (although nonsignificant statistically) and decreases in 9-day sprouts, being significantly smaller than in 5- and 7-day sprouts (Fig. 1 A, B). Concerning the cauliflower treated 9-day sprouts, 10 $\mathrm{mM} \mathrm{NaCl}, 100 \mathrm{mM} \mathrm{NaCl}$ and $10 \mathrm{mM} \mathrm{Na}_{2} \mathrm{SO}_{4}$ caused a $16 \%, 19 \%$ and $20 \%$ decrease of TPC-FC, respectively, compared to 9-day untreated sprouts. The variations of TPC-D280 in the case of these treatments were nonsignificant (Tukey HSD, $\mathrm{p}<0.05$ ), however, comparing with TPC-FC, we notice that $\mathrm{NaCl}$ provoke also reductions, but not $10 \mathrm{mM} \mathrm{Na} 2 \mathrm{SO}_{4}$ which, contrary, is slightly increasing TPC-D280. Most notable was the effect of $\mathrm{Na}_{2} \mathrm{SO}_{4} 100 \mathrm{mM}$, which showed increases up to $66 \%$ for the TPC-FC (from 83.45 to $138.60 \mathrm{mg} \mathrm{GAE} / 100 \mathrm{~g} \mathrm{FW}$ ) and up to $185 \%$ for the TPC-D280 (from 96.19 to 273.79 $\mathrm{mg}$ GAE/100 g FW). The great augmentation of TPCD280 could be due to the $\mathrm{Na}_{2} \mathrm{SO}_{4}$ - stimulated synthesis of some aromatic compounds which do not react with the Folin-Ciocalteu reagent, but absorb light at $280 \mathrm{~nm}$; the identification of such secondary metabolites requires further investigations. Such aromatic compounds may exist in much smaller amounts in untreated sprouts or may be formed only in the case of sodium sulphate treatments and it is probable to belong to the class of aromatic glucosinolates. Kestwal et al. (2011) reported an increase in the aromatic glucosinolates content in case of sulphur treatments, and most likely this is also the case of $\mathrm{Na}_{2} \mathrm{SO}_{4}$ treatment.

In untreated broccoli sprouts, the evolution of total phenols is different from that of cauliflower. Both methods 
462

revealed that TPC decrease from 5- to 7-day sprouts with 24\% (TPC-FC) and 28\% (TPC-D280) and increase from 7- to 9-day sprouts with 9\% (TPC-FC) and 12\% (TPCD280), but without overpassing the 5-day sprouts TPC level; all differences being statistically significant. Nevertheless, treatments influences are similar as in cauliflower, excepting that $10 \mathrm{mM} \mathrm{Na}_{2} \mathrm{SO}_{4}$ is not increasing TPC-D280. $10 \mathrm{mM} \mathrm{NaCl}, 100 \mathrm{mM} \mathrm{NaCl}$ and $10 \mathrm{mM}$ $\mathrm{Na}_{2} \mathrm{SO}_{4}$ are decreasing TPC-FC with $24 \%, 14 \%, 11 \%$ respectively, and TPC-D280 with $18 \%, 8 \%$ and $2 \%$, last two variations being non-significant statistically. Important increases were registered in the case of $100 \mathrm{mM} \mathrm{Na}_{2} \mathrm{SO}_{4}$ treatment: TPC-FC with $32 \%$ (from 71.90 to $95.22 \mathrm{mg}$ GAE/100 g FW) and TPC-D280 with 100\% (from 89.70 to $179.63 \mathrm{mg} \mathrm{GAE} / 100 \mathrm{~g} \mathrm{FW}$ ), but concentration enhancements were more pronounced in case of cauliflower sprouts. Despite the impressive increase of TPC in the case of $100 \mathrm{mM} \mathrm{Na} \mathrm{SO}_{4}$ treatments, this protocol is inconvenient for practical use, as serious inhibitions of germination and sprouts growth were noticed.

Concerning the increase of TPC during different phases of germination, it may be due not only to the biosynthesis and bioaccumulation of polyphenols, but also to the hydrolysis of tannins, glycosylated flavonoids and the degradation of other polymerized polyphenols from seeds. Similar observations were made by Fouad and Rehab (2015), which studied the effects of germination time on lentil sprouts. They observed an increase of TPC during germination with the maximum level at 5-day lentil sprouts, followed by a decrease, which they proposed as due to mobilization of stored phenolics by the activation of enzymes like polyphenol oxidase (Fouad and Rehab, 2015). Activation of polyphenol oxidase could also explain the decrease of TPC in the 7-day broccoli and 9-day cauliflower sprouts of the present work. Korus (2011) studied another Brassica vegetable, the kale, at different stages of maturity and stated that polyphenol oxidase's activity increases with the age of the plant, so this might account for the reduction of TPC with germination time.

The $10 \mathrm{mM}$ and $100 \mathrm{mM} \mathrm{NaCl}$ treatments reduced TPC in both Brassica sprouts (Fig. 1 A, B). Similarly, Yuan et al. (2010) studied radish sprouts and also found that 10 $\mathrm{mM} \mathrm{NaCl}$ diminish TPC in 3-, 5- and 7-day sprouts (without affecting their antioxidant activity), while a 100 $\mathrm{mM} \mathrm{NaCl}$ treatment increase it in 3- and 5-day radish sprouts and slightly decrease it in 7-day sprouts. This clearly indicates that salt influences on the phenolic content of each plant critically depend on the salt sensitivity of the plant and its maturity stage, observations also made in other studies (Kim et al., 2008; Yuan et al., 2010). As far as the influence of the sodium sulphate, we could not find studies regarding the effect of this salt on the TPC of edible sprouts.

\section{Radical scavenging capacity}

In cruciferous sprouts, the radical scavenging capacity (RSC) is mainly due to phenolic compounds present in the plant tissues. In this respect, Zieliński et al. (2007) analysed radish, small radish and rapeseed during the first 7 days of germination and found that phenolics have the most important contribution to the overall antioxidant capacity, followed by ascorbic acid, while soluble proteins, reduced glutathione and tocopherols have minor contributions.
More than that, the number of DPPH ${ }^{\bullet}$ molecules reduced in reactions with phenolic antioxidants is equal to the number of their available hydroxyl groups (Cartea et al., 2011; Roby et al., 2013); i.e., the more free hydroxyl groups present in polyphenols, the greater their radical scavenging capacity.

In untreated cauliflower sprouts, the evolution of RSC reveals a slight increase from 5- to 7-day, followed by a decrease from 7- to 9-day (Fig. 2), similar with TPC-FC and TPC-D280 variations during germination. This similarity highlights that in cauliflower untreated sprouts, the main antioxidants are phenolic compounds. However, in broccoli untreated sprouts, RSC is higher than in cauliflower, although TPC was lower, which indicates that the main antioxidants are not phenolics. This strengthening of antioxidant capacity could be due to the higher content of broccoli sprouts in other antioxidants, such as glucosinolates and their breakdown products, isothiocyanates. Thus, sulforaphane is an isothiocyanate present in broccoli, which proved to have antioxidant properties (de Figueiredo et al., 2015).

In both varieties of sprouts, the treatments with $10 \mathrm{mM}$ and $100 \mathrm{mM} \mathrm{NaCl}$ showed slightly enhanced RSC compared to 9-day untreated sprouts, even if the TPC decreased (Fig. 1 A, B vs. Fig. 2). A possible explanation might be the NaCl-stimulation of other radical scavenging compounds biosynthesis, such as isothiocyanates and glucosinolates. Yuan et al. (2010) found that the total glucosinolate contents in 5- and 7-day-old radish sprouts treated with $100 \mathrm{mM} \mathrm{NaCl}$ increased by $50 \%$ and $127 \%$, respectively; Guo et al. (2013) also, reported that the content of the isothiocyanate sulforaphane in 7-day-old broccoli sprouts treated with $100 \mathrm{mM} \mathrm{NaCl}$ was 2.1 times higher than in the control.

Concerning the sodium sulphate treatments, the responses of the two sprout varieties were very different. The cauliflower sprouts have similar variation as TPC-FC, which means a decrease of RSC in the case of $10 \mathrm{mM}$ $\mathrm{Na}_{2} \mathrm{SO}_{4}$, with 5\% (significant statistically) compared to the untreated 9-day control, whereas in the case of $100 \mathrm{mM}$ $\mathrm{Na}_{2} \mathrm{SO}_{4}$, a strong increase (with 49\%) was noted. In broccoli, $10 \mathrm{mM} \mathrm{Na}_{2} \mathrm{SO}_{4}$ induced an increase of RSC (about 3\%, although non-significant statistically), but the $100 \mathrm{mM} \mathrm{Na} 2 \mathrm{SO}_{4}$ treatment decreased the RSC by $6 \%$. These variations are not in accordance with TPC changes. An explanation will be presented in the following paragraph, but further investigations are needed, as the scientific literature concerning the effects of sodium sulphate on plants antioxidant properties is very scarce at the present time.

Salinity stress is known to be accompanied by enhancement of reactive oxygen species production in plants (Gupta and Huang, 2014). As a normal defence mechanism, plants activate their antioxidant potential, which means increased activity of antioxidant enzymes, but also, biosynthesis of well-known antioxidants, such as polyphenols, ascorbic acid and others. This explains the increase of TPC in the case of $100 \mathrm{mM} \mathrm{Na} 2 \mathrm{SO}_{4}$. An explanation for the decrease of RSC in broccoli sprouts under $100 \mathrm{mM} \mathrm{Na} 2 \mathrm{SO}_{4}$ treatment may be the intense perturbation of biochemical and physiological plant systems by the aggressive salt stress, together with the endogenous 
generation of a very big quantity of reactive oxygen species, which "consume" the plant polyphenols and other existing antioxidants.

If the results are analysed from the point of view of sulphur supplementation, our observations are different from those of Kestwal et al. (2011), who studied the sodium thiosulphate $\left(\mathrm{Na}_{2} \mathrm{~S}_{2} \mathrm{O}_{3}\right)$ influence in 12-day cruciferous sprouts. They noticed that different concentrations of sulphur supplementation, increased TPC-FC and DPPH radical scavenging activity of radish and broccoli sprouts, but they did not affect the levels significantly in cabbage sprouts. They have also claimed that sulphur fertilisation stimulates the synthesis of aliphatic glucosinolates, but not of aromatic glucosinolates (Kestwal et al., 2011). Possible reasons for the disagreement between our results and those of their study could be the differences for the S-containing anion ( $\mathrm{SO}_{4}{ }^{2-}$ and respectively, $\mathrm{S}_{2} \mathrm{O}_{3}{ }^{2-}$ ), the duration and conditions of sprouting, as well as, the different broccoli cultivars employed in the two studies.

\section{Anthocyanin content}

Broccoli sprouts of the studied variety - 'Premium' did not contain anthocyanins. Although broccoli sprouts do not usually contain anthocyanin pigments, there are few varieties containing small amounts, about $0.2-0.3 \mathrm{mg} / 100 \mathrm{~g}$ FW, or even $0.6 \mathrm{mg} / 100 \mathrm{~g} \mathrm{FW}$ in case of the 'Viola' purple broccoli 7-day-old sprouts (Moreno et al., 2010).

In 'Gigante di Napoli' cauliflower sprouts, a considerable amount of monomeric anthocyanins was found, ranging between 2.77-6.48 mg/100 g FW in untreated sprouts (Fig. 3). The presence of anthocyanins in cauliflower contributes to its higher content in total phenolics, compared to broccoli sprouts. A constant decrease of AC was noted from 5-day to 7-day and 9-day sprouts, although non-significant statistically. Both sodium salts treatments increased AC in 9-day cauliflower sprouts and the augmentation is more important when salt concentration increased. Moreover, $\mathrm{Na}_{2} \mathrm{SO}_{4}$ treatments stimulated more than $\mathrm{NaCl}$ the anthocyanins accumulation, causing an increase by $1.33 \mathrm{mg} / 100 \mathrm{~g} \mathrm{FW}$ in case of $10 \mathrm{mM} \mathrm{Na}_{2} \mathrm{SO}_{4}$, to $8.23 \mathrm{mg} / 100 \mathrm{~g} \mathrm{FW}$ in case of $100 \mathrm{mM} \mathrm{Na} \mathrm{SO}_{4}$ treatment (compared to the 9-day untreated sprouts).

The present results are in accordance with previous studies, as Dkhil and Denden (2012) who found that anthocyanin content increased in 15-day-old okra seedlings grown in the presence of $\mathrm{NaCl}$ and the increase was greater at higher salt concentrations $(80 \mathrm{mM}$ and $100 \mathrm{mM} \mathrm{NaCl})$.

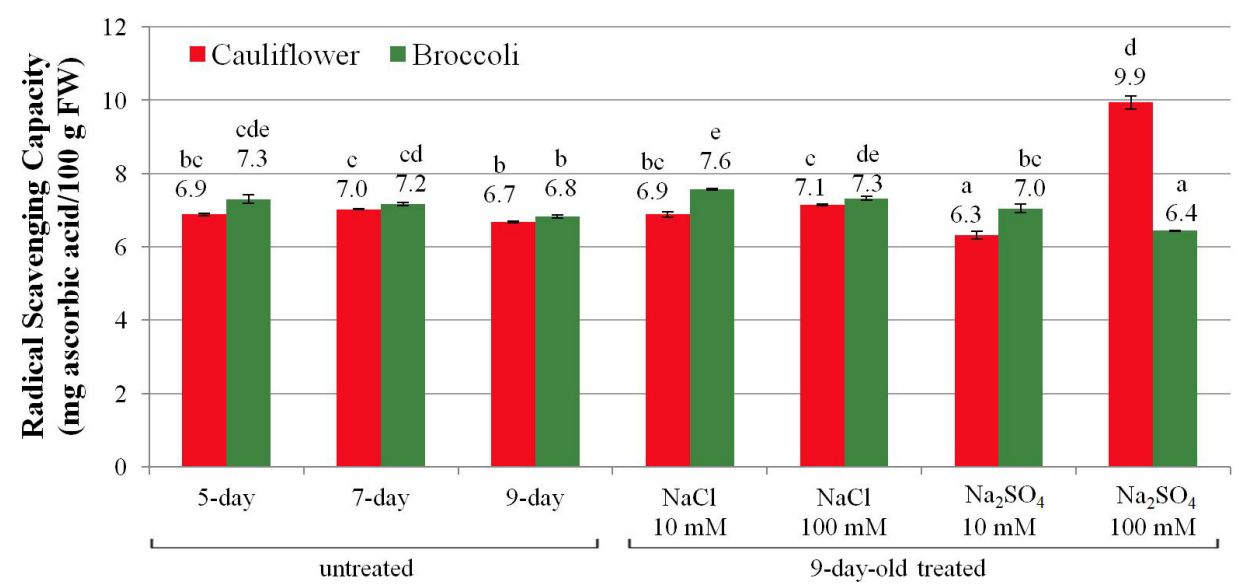

Fig. 2. Radical scavenging capacity of untreated (5-, 7- and 9-day-old) and 9-day-old treated (with $\mathrm{NaCl}_{\text {or }} \mathrm{Na}_{2} \mathrm{SO}_{4}$ ) cauliflower and broccoli sprouts. Different letters denote significant differences between variants of same variety (Tukey HSD test, $\mathrm{p}<0.05$ )

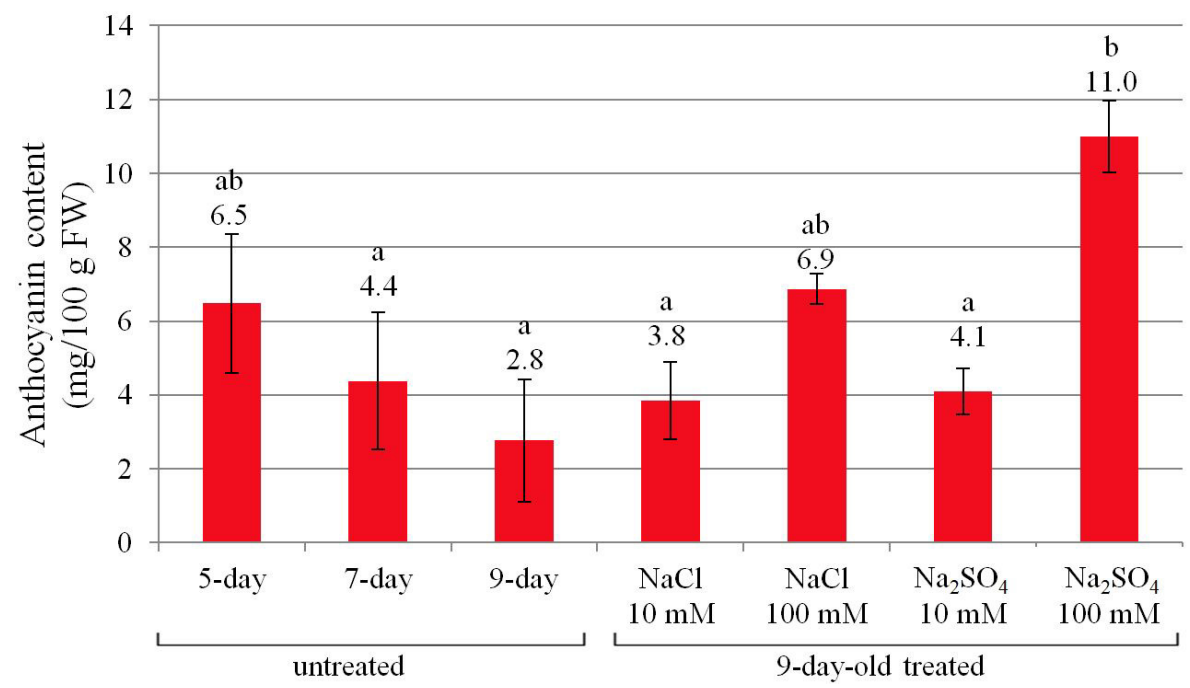

Fig. 3. Anthocyanin content of untreated (5-, 7- and 9-day-old) and 9-day-old treated (with $\mathrm{NaCl}_{0}$ or $\mathrm{Na}_{2} \mathrm{SO}_{4}$ ) cauliflower sprouts. Different letters denote significant differences (Tukey HSD test, $\mathrm{p}<0.05$ ). 
464

Correlation analyses

Between the two techniques used to measure phenolic content (TPC-FC and TPC-D280) high correlations were noted; for cauliflower: $\mathrm{R}^{2}=0.8663, \mathrm{p}<0.05$ and broccoli: $\mathrm{R}^{2}=0.8116, \mathrm{p}<0.05$, justifying their appropriateness for total phenolic content determination. Anthocyanin content of cauliflower sprouts correlated well with TPC-D280 $\left(\mathrm{R}^{2}\right.$ $=0.7173, \mathrm{p}<0.05)$, better with RSC $\left(\mathrm{R}^{2}=0.7974, \mathrm{p}<\right.$ $0.05)$ and moderately with TPC-FC $\left(\mathrm{R}^{2}=0.5601, \mathrm{p}<\right.$ $0.05)$.

For cauliflower sprouts a strong correlation between TPC-FC and RSC $\left(\mathrm{R}^{2}=0.7613, \mathrm{p}<0.05\right)$ and a higher one between TPC-D280 and RSC $\left(\mathrm{R}^{2}=0.9360, \mathrm{p}<0.05\right)$ were noted. Contrary, in broccoli sprouts, no correlations were found between TPC-FC and RSC or between TPC-D280 and RSC. Overall, such relationships concur with previous observations, that phenolic compounds are the main antioxidants in cauliflower sprouts, but not in broccoli sprouts.

\section{Conclusions}

The present research revealed that even if 9-day-old is not the maturity level with best antioxidant characteristics, both sodium salts treatments improved the antioxidant properties of studied sprouts, by increasing cumulatively or individually the following: total phenolic content, anthocyanin content, radical scavenging capacity. Sodium sulphate treatments at high concentration $(100 \mathrm{mM}$ $\mathrm{Na}_{2} \mathrm{SO}_{4}$ ) stimulate much more the accumulation of total polyphenols and soluble dry matter in cauliflower and broccoli sprouts, compared to sodium chloride of identical concentration. Similar increase was observed for the anthocyanin content of cauliflower sprouts. While this study confirmed that phenolic compounds are the main antioxidants in cauliflower, this cannot be concluded in the case of broccoli sprouts. Further studies are needed in order to elucidate the differences between the two Brassica oleracea varieties, the response mechanisms triggered by sodium sulphate applied in high concentrations during sprouting and to optimize the level and time-schedule of treatments. Germination under adequate salt stress conditions might be important as a way to enrich sprouts in polyphenols and to transform them in "biofactories" of health-promoting compounds.

\section{Acknowledgements}

This work was supported by UEFISCDI, grant number PN III - 3.1., $48 \mathrm{BM} / 2016$, "New methods to increase the bealth-promoting potential of sprouts".

\section{References}

Baenas N, García-Viguera C, Moreno DA (2014). Elicitation: a tool for enriching the bioactive composition of foods. Molecules 19(9):1354113563.

Brand-Williams W, Cuvelier ME, Berset C (1995). Use of a free radical method to evaluate antioxidant activity. LWT - Food Science and Technology 28(1):25-30.
Cartea ME, Francisco M, Soengas P, Velasco P (2011). Phenolic compounds in Brassica vegetables-Review. Molecules 16:251-280.

Cevallos-Casals BA, Cisneros-Zevallos L (2010). Impact of germination on phenolic content and antioxidant activity of 13 edible seed species. Food Chemistry 119(4):1485-1490.

de Figueiredo SM, Binda NS, Nogueira-Machado JA, Vieira-Filho SA, Caligiorne RB (2015). The antioxidant properties of organosulfur compounds (sulforaphane). Recent Patents on Endocrine, Metabolic \&ImmuneDrug Discovery 9(1):24-39.

Dkhil BB, Denden M (2010). Salt stress induced changes in germination, sugars, starch and enzyme of carbohydrate metabolism in Abelmoschus esculentus (L.) Moench seeds.African Journal of Agricultural Research 5(12):1412-1418

Dkhil BB, Denden M (2012). Effect of salt stress on growth, anthocyanins, membrane permeability and chlorophyll fluorescence of Okra (Abelmoschus esculentus L.) seedlings. American Journal of Plant Physiology 7:174183.

Fouad AA, Rehab FM (2015). Effect of germination time on proximate analysis, bioactive compounds and antioxidant activity of lentil (Lens culinaris Medik.) sprouts. Acta Scientiarum Polonorum Technologia Alimentaria 14(3):233-246.

Frias J, Miranda ML, Doblado R, Vidal-Valverde C (2005). Effect of germination and fermentation on the antioxidant vitamin content and antioxidant capacity of Lupinus albus L. var. Multolupa.Food Chemistry $92(2): 211-220$.

GulewiczP, Martinez-Villaluenga C, Kasprowicz-Potocka M, FriasJ (2014). Non-nutritive compounds in Fabaceae family seeds and the improvement of their nutritional quality by traditional processing - a review. Polish Journal of Food and Nutrition Sciences 64(2):75-89.

Guo RF, Yuan GF, Wang QM (2013). Effect of $\mathrm{NaCl}$ treatments on gucosinolate metabolism in broccoli sprouts. Journal of Zhejiang University.Science B 14(2):124131.

Gupta B, Huang B (2014). Mechanism of salinity tolerance in plants: physiological, biochemical, and molecular characterization. International Journal of Genomics 2014:1-18.

Jacobo-Velázquez DA, Cisneros-Zevallos L (2012). An alternative use of horticultural crops: stressed plants as biofactories of bioactive phenolic compounds. Agriculture 2(3):259-271.

Kaulmann A, Jonville MC, Schneider YJ, Hoffmann L, Bohn T (2014). Carotenoids, polyphenols and micronutrient profiles of Brassica oleraceae and plum varieties and their contribution to measures of total antioxidant capacity. Food Chemistry 155:240-250.

Kestwal RM, Lin JC, Bagal-Kestwal D, Chiang BH (2011). Glucosinolates fortification of cruciferous sprouts by sulphur supplementation during cultivation to enhance anti-cancer activity. Food Chemistry 126(3):1164-1171.

Kevers C, Falkowski M, Tabart J, Defraigne JO, Dommes J, Pincemail J (2007).Evolution of antioxidant capacity during storage of selected fruits and vegetables.Journal of Agricultural and Food Chemistry 55(21):8596-8603.

Kim HJ, Fonseca JM, Choi JH, Kubota C, Kwon DY (2008). Salt in irrigation water affects the nutritional and visual properties of romaine lettuce (Lactuca sativa L.).Journal of Agricultural and Food 
Chemistry 56(10):3772-3776

Korus A (2011). Level of vitamin C, polyphenols, and antioxidant and enzymatic activity in three varieties of kale (Brassica oleracea L. var. Acephala) at different stages of maturity. International Journal of Food Properties 14(5):1069-1080.

Lim JH, Park KJ, Jeong JW, Park JJ, Kim BK, Kim JC, Jeong SW (2013). Antioxidant activity and antioxidant compounds in edible sprouts. The Official Journal of Federation of American Societies for Experimental Biology 27(1):260.

López-Amorós ML, Hernández T, Estrella I (2006). Effect of germination on legume phenolic compounds and their antioxidant activity. Journal of Food Composition and Analysis 19(4):277-283.

Moreira-Rodríguez M, Nair V, Benavides J, Cisneros-Zevallos L, JacoboVelázquez DA (2017). UVA, UVB light doses and harvesting time differentially tailor glucosinolate and phenolic profiles in broccoli sprouts. Molecules 22(7):1065-1088.

Moreno DA, Pérez-Balibrea S, Ferreres F, Gil--zquierdo Á, García-Viguera C. (2010). Acylated anthocyanins in broccoli sprouts. Food Chemistry 123(2):358-363.

Patras A, Luchian CE, Niculaua M,Stoleru V (2013). Effects of some abiotic factors on Brassica Oleracea var. capitata sprouts. Bulletin of the University of Agricultural Sciences and Veterinary Medicine ClujNapoca. Horticulture 70(1):172-179.

Podsędek A (2007). Natural antioxidants and antioxidant capacity of Brassica vegetables: A review. LWT-Food Science and Technology 40(1):1-11.

Ragusa L, Picchi V, Tribulato A, Cavallaro C, Lo Scalzo R, Branca F (2016). The effect of the germination temperature on the phytochemical content of broccoli and rocket sprouts. International Journal of Food Sciences and Nutrition 68(4):411-420.

Ribéreau-Gayon P, Glories Y, Maujean A, Dubourdieu D (2006). Phenolic compounds. In: Handbook of Enology, Vol 2. The chemistry of wine stabilization and treatments. John Wiley Sons Ltd, Chichester pp 141203.
Roby MHH, Sarhan MA, Selim KAH, Khalel KI (2013). Evaluation of antioxidant activity, total phenols and phenolic compounds in thyme (Thymus vulgaris L.), sage (Salvia officinalis L.), and marjoram (Origanum majorana L.) extracts. Industrial Crops and Products 43:827-831.

Soengas P, Cartea ME, Francisco M, Sotelo T, Velasco P (2012). New insights into antioxidant activity of Brassica crops. Food Chemistry 134(2):725-733.

Sousa C, Valentão P, Pereira DM, Taveira M, Ferreres F, Pereira JA, Bento A, Seabra RM, Andrade PB (2009). Phytochemical and antioxidant characterization of Brassica oleraceae var. costata extracts. In: Govil JN, Singh VK (Eds). Recent progress on medicinal plants, Vol 24. Standardization of herbal/ayurvedic formulations. Studium Press, LLC pp311-339.

Vale AP, Santos J, Brito NV, Marinho C, Amorim V, Rosa E, Oliveira MBP (2015). Effect of refrigerated storage on the bioactive compounds and microbial quality of Brassica oleraceae sprouts. Postharvest Biology and Technology 109:120-129.

Wang WB, Kim YH, Lee HS, Kim KY, Deng XP, Kwak SS (2009). Analysis of antioxidant enzyme activity during germination of alfalfa under salt and drought stresses. Plant Physiology and Biochemistry 47(7):570-577.

Yuan G, Wang X, Guo R, Wang Q (2010). Effect of salt stress on phenolic compounds, glucosinolates, myrosinase and antioxidant activity in radish sprouts. Food Chemistry 121(4):10141019.

Zielinski H, Piskula MK, Michalska A, Kozlowska H (2007). Antioxidant capacity and its components of cruciferous sprouts. Polish Journal of Food and Nutrition Sciences 57(3):315-321. 